\title{
POST-TRAUMATIC STRESS DISORDER AND AFFECTING FACTORS IN PREGNANT WOMEN IN THE COVID-19 PANDEMIC
}

\author{
Pınar Kara ${ }^{1}$, Evşen Nazik ${ }^{2}$, Hakan Nazik ${ }^{3} \&$ Dilara Özer ${ }^{3}$ \\ ${ }^{1}$ Nursing Department, Department of Obstetrics and Gynecology Nursing, Niğde Ömer Halisdemir University, \\ Niğde Zübeyde Hanım School of Health, Niğde, Turkey \\ ${ }^{2}$ Nursing Department, Department of Obstetrics and Gynecology Nursing, \\ Çukurova University Faculty of Health Sciences, Adana, Turkey \\ ${ }^{3}$ Department of Gynecology and Obstetrics, Adana City Training and Research Hospital, Adana, Turkey
}

received: 26.3.2021;

revised: 3.5.2021;

accepted: 6.5.2021

\begin{abstract}
SUMMARY
Background: Post-traumatic stress disorder (PTSD) causes adverse obstetric outcomes in pregnants. COVID-19 pandemic can cause PTSD symptoms in pregnant women. This descriptive study aims to determine the post-traumatic stress disorder and affecting factors in pregnant women in the COVID-19 pandemic.

Subjects and methods: A total of 445 pregnant women completed "Data Collection Form" and "DSM-5 Post-Traumatic Stress Disorder Checklist (PCL-5)".

Results: The mean total PCL-5 score of the pregnant women was found to be 57.27士17.90. There was a significant difference between PCL-5 and gestational week, parity, the idea that the COVID-19 outbreak would cause a problem in childbirth, the presence of a COVID-19 in one of the family members/a loved one, the status of following COVID-19 -related developments $(p<0.05)$.

Conclusions: It is important for health professionals to evaluate the psychological effects of the pandemic in pregnants during antenatal period.
\end{abstract}

Key words: SARS-CoV-2 - pregnancy - post-traumatic stress disorder - health professional

$$
\text { * } * * * * *
$$

\section{INTRODUCTION}

COVID-19 has emerged as a case of pneumonia of unknown cause, characterized by symptoms of upper respiratory tract infection in Wuhan, Hubei Province, China (Wu et al. 2020a). The World Health Organization (WHO) declared this situation as a pandemic on December 31, 2019 (WHO 2021a). This virus was called COVID-19 (SARS-CoV-2) because it was different from previously identified coronavirus species on January 7, 2020. COVID-19 has spread rapidly to many countries globally. 124,535,520 individuals around the world were infected with COVID-19 and 2,738,876 people died due to it as of March 25, 2021 (WHO 2021b). The total number of COVID-19 cases in Turkey is reported to be 3,091,282 and the number of deaths is 30,462 (Ministry of Health 2021). COVID-19 infection continues to spread, and casualties are increasing day by day even though every country around the world takes its own measures to combat this global pandemic (WHO 2021b).

The COVID-19 pandemic also leads to increased stress levels and post-traumatic stress disorder symptoms in addition to its physical effects resulting in death (WHO 2021c). Post-traumatic stress disorder (PTSD) is defined as a chronic mental health problem seen after frightening life events (attack, rape, accidents, disasters, etc.) and accompanied by symptoms such as reexperiencing the trauma, avoiding thoughts, emotions, and interactions that remind you the trauma, negative changes in cognition and mood and difficulty falling asleep, irritability, easy startling, difficulty in focusing your thoughts (Eren Koçak \& Kılıç 2017). PTSD usually occurs 1 month after the traumatic event and its effect may last for years (Psychiatric Association of Turkey 2021). PTSD is reported to be more likely to occur in pregnant women in the literature (Li \& Graham 2017). A meta-analysis of 24,267 women reported that the mean prevalence of PTSD during pregnancy was $3.3 \%$ (95\% $\mathrm{CI}=2.44-4.54)$ and $18.95 \%$ (95\% $\mathrm{CI}=10.62$ 31.43) of women in the high-risk group had a higher risk of PTSD during pregnancy (Dikmen Yildiz et al. 2017). Obstetric (preeclampsia, history of postpartum hemorrhage, fetal complications and hyperemesis gravidarum), psychiatric (perinatal and antenatal psychiatric history, traumatic life events and fear of childbirth), social (lack of antenatal social support), (Cirino \& Knapp 2019) and hormonal (low estradiol levels) (Li \& Graham 2017) factors pose a risk in PTSD during pregnancy. Post-traumatic stress disorder causes maternalfetal negative results such as ectopic pregnancy, abortion, hyperemesis gravidarum, preterm birth, low birth weight, is intrauterine growth retardation (IUGR) in pregnant women (Cook et al. 2018).

The COVID-19 pandemic has created a global crisis and necessitated a change in many areas. Physical and social isolation measures taken in the current process, changes in daily routines, threats of financial loss, insecurities in food access, uncertainty about the future, and many potential factors that cause stress are intensely 
experienced due to the pandemic (Esterwood \& Saeed 2020). Pregnant women are in a more fragile and disadvantaged position during the pandemic process (Yassa et al. 2020) due to more frequent emotional fluctuations and psychological changes (Bjelica et al. 2018). PTSD symptoms have been reported to occur in pregnant women during this crisis process on a global scale (Berthelot et al. 2020, Hocaoglu et al. 2020, Liu et al. 2021, Zhou et al. 2020). High levels of grief (Liu et al. 2021), education (Berthelot et al. 2020, Hocaoglu et al. 2020), and income level (Berthelot et al. 2020) are reported to be effective in PTSD symptoms experienced during this process. It is noted that the data on PTSD symptoms caused by the pandemic in pregnant women are limited and the effects of the pandemic on PTSD symptoms in pregnant women are uncertain even though several studies have shown that the presence of COVID-19-related symptoms (Hocaoglu et al. 2020) and a high level of COVID-19-related health anxiety (Liu et al. 2021) of pregnant women are associated with PTSD symptoms. Correct interventions should be made in the early period to improve the quality of maternal and fetal health care and to ensure optimal care during the pandemic. It is important to determine the symptoms of post-traumatic stress disorder and affecting factors in pregnant women in order to manage this global outbreak effectively. Therefore, this study aims to determine the post-traumatic stress disorder symptoms and affecting factors of pregnant women in the COVID-19 pandemic.

\section{SUBJECTS AND METHODS}

\section{Participants and procedure}

This descriptive study was conducted in obstetrics outpatient clinics of a training and research hospital in Turkey. The population of the study consisted of pregnant women who came to routine antenatal followup between July and December 2020. Power analysis was performed for the sample size. It was determined based on Demirezen's (2019) study that at least 405 pregnant women were required with $80 \%$ power and $5 \%$ error level with a difference of 5\% (Demirezen 2019). The study was completed with 445 pregnant women who met the inclusion criteria. Inclusion criteria were (1) being >18 years old, (2) not having any diagnosed mental health problems, (3) not receiving psychiatric treatment, (4) accepting COVID-19 as a stressful event, (5) not having any risk during pregnancy, (6) not having experienced any traumatic event (attack, rape, accidents, disasters, death, etc.) in the last 1 month, (7) being able to understand and answer the questions, and (8) volunteering to participate in the study.

\section{Measures}

"Data Collection Form" and "DSM-5 Post-Traumatic Stress Disorder Checklist (PCL-5)" were used to collect the data (authors' note: DSM-5 is final version Diagnostic and Statistical Manual of Mental Disorders).

\section{Data collection form}

The form was developed by the researchers in line with the literature The form was developed by the researchers in line with the literature (Ministry of Health 2021, WHO 2021a, Wu et al. 2020a, Yassa et al. 2020). The form included 20 questions about the socio-demographic characteristics of pregnant women (age, educational status, current place of residence, perception of monthly income level, etc.) and their thoughts and practices towards the COVID-19 pandemic (thinking that the pandemic causes a problem in pregnancy/childbirth, practices during the pandemic process, etc.).

\section{DSM-5 post-traumatic stress disorder checklist (PCL-5)}

The latest version of PCL, which was created as 17 items according to Diagnostic and Statistical Manual of Mental Disorders-III-Revision (DSM-III-R) and commonly used to measure PTSD symptoms in the clinical field according to DSM-5, was made by Weathers et al. (2013). The self-reported scale consists of 20 questions to determine to what extent individuals who have experienced a very stressful/traumatic event are uncomfortable with the symptoms they have experienced related to that event in the last month. The scale is a 5-point Likert type and in each question, individuals are asked to rate the severity of their experiences between (0) and (4) (Weathers et al. 2013). The Turkish validity and reliability of the scale were performed by Boysan et al. (2017) and 4 sub-scales were obtained. These sub-scales were re-experiencing, avoidance, negative alterations, and hyperarousal. The highest score that can be obtained from the scale is 80 . The Cronbach's alpha value of the scale was determined as 0.97 (Boysan et al. 2017). The Cronbach's alpha value of the scale was obtained as 0.95 in this study.

\section{Data collection}

Data collection tools were applied to pregnant women between 09-16 hours on working days in the Obstetrics Outpatient Clinic of the training and research hospital where the study was conducted. The data were collected by face-to-face interview method. The collection of data collection forms took approximately 15-20 minutes.

\section{Statistical analysis}

SPSS software (IBM Corp., Armonk, NY, v. 24.0) was used. The suitability of the data for normal distribution was evaluated by the Kolmogorov Smirnov test before starting the analysis. Descriptive statistics were given number (n), percentage (\%), mean, and standard deviation (Mean \pm SD) values. Independent sample t-test (student t-test) was used to compare two independent groups and analysis of variance test (ANOVA) was used to compare three and more independent groups. Tukey or Tamhane's T2 posthoc tests were performed for three or more groups with statistically significant different vari- 
ables in binary comparisons according to the homogeneity of variances. Pearson's correlation test was used to determine the relationships between numerical variables. Statistical significance level was taken as $p<0.05$.

\section{RESULTS}

It was determined that $37.3 \%$ of the pregnant women participating in the study were between the ages of 19 26 and the mean age was $29.69 \pm 6.93$ years. It was found that $33.3 \%$ of the pregnant women were high school graduates, $77.8 \%$ were unemployed, $69.9 \%$ had spouses working, and $78.9 \%$ had nuclear family types. Approximately half $(51.3 \%)$ of the participants lived in the city center and perceived their income as less than their expense $(55.5 \%)$. It was determined that more than half $(56.0 \%)$ of the pregnant women planned their pregnancy, $44.3 \%$ were in the last trimester $\left(\geq 28^{\text {th }}\right.$ weeks), $31.5 \%$ experienced their first pregnancy, and $31.9 \%$ never gave birth (Table 1 ).

It was determined that $20.2 \%$ of the pregnant women participating in the study did not regularly go to the hospital for antenatal visit related to their current pregnancy due to the COVID-19 pandemic. $21.6 \%$ of the participants stated that they thought that they would have problems during pregnancy due to the COVID-19, 69.8\% of these pregnant women thought that the fetus would be infected with COVID-19, and $30.2 \%$ thought that it would cause premature birth. $23.6 \%$ of pregnant women reported that they thought their baby would be infected with COVID-19 during childbirth. It was determined in this process that all pregnant women wore masks, washed their hands (100\%), $10.8 \%$ paid attention to the social distance rule, $4.5 \%$ avoided listening, watching or reading to news, $68.5 \%$ did not go out unless there was an emergency, $14.6 \%$ never went out, $21.8 \%$ listened to music, $15.7 \%$ read books, $38.9 \%$ talked to their friends/ loved ones by phone, $2.7 \%$ received psychological support, and $2.0 \%$ called the psychological support line of the Ministry of Health. It was found that almost all of the pregnant women $(91.2 \%)$ followed the developments related to COVID-19, and the vast majority of these follow-ups $(83.6 \%)$ were $\mathrm{TV}$ news and social media tools $(39.8 \%) .60 .0 \%$ of the participants stated that they followed the number of COVID-19 cases/deaths/ recovering patients in Turkey. $21.6 \%$ of pregnant women reported that one of the family members or a loved one had COVID-19 (Table 2).

The mean scores of the pregnant women in the reexperiencing, avoidance, negative alterations, hyperarousal sub-scales and total of the PCL-5 scale were found to be $13.81 \pm 4.71,5.64 \pm 1.92,20.00 \pm 6.43,17.81 \pm 5.75$, and $57.27 \pm 17.90$, respectively (Table 3 ).

It was determined that there was no statistically significant difference between the mean PCL-5 scale scores of the pregnant women participating in the study with the idea that age, education level, employment status, family type, current place of residence, perception
Table 1. Descriptive and obstetric characteristics of pregnant women $(n=445)$

\begin{tabular}{|c|c|c|}
\hline Variable & $\mathrm{n}$ & $\%$ \\
\hline \multicolumn{3}{|c|}{$\begin{array}{l}\text { Age groups (years) }(\text { Mean } \pm S D=29.69 \pm 6.93 \text {, } \\
\text { Min-Max }=19-47)\end{array}$} \\
\hline $19-26$ & 166 & 37.3 \\
\hline $27-34$ & 159 & 35.7 \\
\hline$\geq 35$ & 120 & 27.0 \\
\hline \multicolumn{3}{|l|}{ Education status attained } \\
\hline Illiterate & 37 & 8.3 \\
\hline Primary school graduate & 100 & 22.5 \\
\hline Secondary school graduate & 115 & 25.8 \\
\hline High school graduate & 148 & 33.3 \\
\hline University graduate and higher & 45 & 10.1 \\
\hline \multicolumn{3}{|l|}{ Employment status } \\
\hline Employed & 99 & 22.2 \\
\hline Unemployed & 346 & 77.8 \\
\hline \multicolumn{3}{|l|}{ Spouse's employment status } \\
\hline Employed & 311 & 69.9 \\
\hline Unemployed & 134 & 30.1 \\
\hline \multicolumn{3}{|l|}{ Family type } \\
\hline Nuclear & 351 & 78.9 \\
\hline Extended & 94 & 21.1 \\
\hline \multicolumn{3}{|l|}{ Current place of residence } \\
\hline Provincial center & 228 & 51.3 \\
\hline County & 155 & 34.8 \\
\hline Village or Town & 62 & 13.9 \\
\hline \multicolumn{3}{|l|}{ Perception of monthly income level } \\
\hline Expenses less than income & 247 & 55.5 \\
\hline Expenses equal to income & 86 & 19.3 \\
\hline Expenses more than income & 112 & 25.2 \\
\hline \multicolumn{3}{|l|}{ Planning pregnancy } \\
\hline Yes & 249 & 56.0 \\
\hline No & 196 & 44.0 \\
\hline \multicolumn{3}{|c|}{$\begin{array}{l}\text { Gestational week }(\text { Mean } \pm \text { SD }=24.41 \pm 6.93 \text {, } \\
\text { Min-Max }=4-40)\end{array}$} \\
\hline$\leq 12^{\text {th }}$ week & 66 & 14.8 \\
\hline $13-27$ weeks & 182 & 40.9 \\
\hline$\geq 28^{\text {th }}$ week & 197 & 44.3 \\
\hline \multicolumn{3}{|l|}{ Gravida } \\
\hline 1 & 140 & 31.5 \\
\hline 2 & 88 & 19.8 \\
\hline 3 & 77 & 17.3 \\
\hline$\geq 4$ & 140 & 31.4 \\
\hline \multicolumn{3}{|l|}{ Parity } \\
\hline Nulliparty & 142 & 31.9 \\
\hline 1 & 117 & 26.3 \\
\hline 2 & 90 & 20.2 \\
\hline 3 & 59 & 13.3 \\
\hline$\geq 4$ & 37 & 8.3 \\
\hline
\end{tabular}

Abbreviations: SD: mean; SD: standard deviation

of monthly income level, pregnancy planning, gravidity, going to regular antenatal visit, and COVID-19 would cause a problem in pregnancy $(p>0.05)$. It was found in the study that the mean total PCL-5 scores of the pregnant women who were in their first trimester ( $\leq 12^{\text {th }}$ week), gave 1 birth, thought that the COVID-19 would cause a problem in childbirth, one of the family members/a loved one had COVID-19 and followed the 
Table 2. Thoughts and practices of pregnant women towards the COVID-19 pandemic $(n=445)$

\begin{tabular}{|c|c|c|}
\hline Thoughts and practices towards the COVID-19 pandemic & $\mathrm{n}$ & $\%$ \\
\hline \multicolumn{3}{|c|}{ Going to the hospital for antenatal visit regularly since the COVID-19 pandemic } \\
\hline Yes & 355 & 79.8 \\
\hline No (Due to COVID-19 pandemic) & 90 & 20.2 \\
\hline \multicolumn{3}{|l|}{ Thinking that COVID-19 may cause problem in pregnancy } \\
\hline Yes & 96 & 21.6 \\
\hline No & 349 & 78.4 \\
\hline \multicolumn{3}{|c|}{ Problems that pregnant women think may caused by COVID-19 in their pregnancy $(n=96)$} \\
\hline Thinking that the fetus may be infected with COVID-19 & 67 & 69.8 \\
\hline Premature birth risk & 29 & 30.2 \\
\hline \multicolumn{3}{|l|}{ Thinking that COVID-19 may cause a problem during childbirth } \\
\hline Yes (Thinking that the baby may infected with COVID-19) & 105 & 23.6 \\
\hline No & 340 & 76.4 \\
\hline \multicolumn{3}{|l|}{ Practices in the COVID-19 pandemic* } \\
\hline Wearing masks and washing hands & 455 & 100 \\
\hline Paying attention to the personal distance & 48 & 10.8 \\
\hline Avoiding listening, whatching or reading to news & 20 & 4.5 \\
\hline Not going out unless there is an emergency & 305 & 68.5 \\
\hline Never going out & 65 & 14.6 \\
\hline Listen to music & 97 & 21.8 \\
\hline Reading & 70 & 15.7 \\
\hline Making phone calls to friends/loved people & 173 & 38.9 \\
\hline Receiving psychological support & 12 & 2.7 \\
\hline Calling the psychological support line of the Ministry of Health & 9 & 2.0 \\
\hline \multicolumn{3}{|l|}{ Following COVID-19-related developments } \\
\hline Yes & 406 & 91.2 \\
\hline No & 39 & 8.8 \\
\hline \multicolumn{3}{|l|}{ Following COVID-19-related developments $(n=406)^{*}$} \\
\hline TV news & 372 & 83.6 \\
\hline Ministry of Health website & 45 & 10.1 \\
\hline World Health Organization website & 11 & 2.5 \\
\hline Social media tools & 177 & 39.8 \\
\hline \multicolumn{3}{|c|}{ Monitoring the number of COVID-19 cases/deaths/recovering patients in Turkey } \\
\hline Yes & 267 & 60.0 \\
\hline No & 178 & 40.0 \\
\hline \multicolumn{3}{|l|}{ COVID-19 in one of the family members/a loved one } \\
\hline Yes & 96 & 21.6 \\
\hline No & 349 & 78.4 \\
\hline
\end{tabular}

Note: * increased by $\mathrm{n}$ times due to the selection of multiple options

developments related to COVID-19 were higher. A significant difference was found between PCL-5 and gestational week, parity, the thinking that the COVID-19 would cause a problem in childbirth, the presence of a COVID-19 in one of the family members/a loved one, the status of following COVID-19-related developments $(p<0.05)$ (Table 4).

It was determined that there was a positive and weak relationship between the number of COVID-19 cases/ deaths/recovering patients in Turkey and the total mean scores of the PCL-5 scale of pregnant women ( $\mathrm{r}=0.268$, $\mathrm{r}=0.319$ and $\mathrm{r}=0.222$, respectively; $p<0.001$ ) (Table 5).
Table 3. The mean scores of PCL-5 scale and subscales of the pregnant women $(n=445)$

\begin{tabular}{lcc}
\hline PCL-5 total and subscales & Min-Max & Mean \pm SD \\
\hline Re-experiencing subscale & $0-20$ & $13.81 \pm 4.71$ \\
Avoidance subscale & $0-8$ & $5.64 \pm 1.92$ \\
Negative alterations subscale & $0-28$ & $20.00 \pm 6.43$ \\
Hyperarousal subscale & $0-24$ & $17.81 \pm 5.75$ \\
Total & $0-80$ & $57.27 \pm 17.90$ \\
\hline
\end{tabular}

Abbreviations: mean; SD, standard deviation;

PCL-5, DSM-5 post-traumatic stress disorder checklist 
Table 4. Assessing with one-way ANOVA and Independent sample t-test of the relationship between characteristics and thoughts and practices towards the COVID-19 pandemic and total mean scores of PCL-5 of the pregnant women ( $\mathrm{n}=445$ )

\begin{tabular}{|c|c|c|c|c|}
\hline Variables & & Mean \pm SD & $\begin{array}{l}\text { ANOVA } \\
\mathrm{F} \text { and } \mathrm{p} \\
\text { values }\end{array}$ & $\begin{array}{c}\mathrm{t} \text { test } \\
\mathrm{t} \text { and } \mathrm{p} \text { values }\end{array}$ \\
\hline Age groups (years) & $\begin{array}{l}19-26 \\
27-34 \\
\geq 35\end{array}$ & $\begin{array}{l}57.40 \pm 19.79 \\
56.80 \pm 17.70 \\
57.72 \pm 15.36\end{array}$ & $\begin{array}{l}F=0.097 \\
p=0.896\end{array}$ & \\
\hline Education status attained & $\begin{array}{l}\text { Illiterate } \\
\text { Primary school graduate } \\
\text { Secondary school graduate } \\
\text { High school graduate } \\
\text { University graduate and higher }\end{array}$ & $\begin{array}{l}51.54 \pm 17.67 \\
56.68 \pm 19.75 \\
56.37 \pm 16.90 \\
59.68 \pm 17.46 \\
57.41 \pm 17.04\end{array}$ & $\begin{array}{l}F=1.734 \\
p=0.141\end{array}$ & \\
\hline Employment status & $\begin{array}{l}\text { Employed } \\
\text { Unemployed }\end{array}$ & $\begin{array}{l}56.99 \pm 17.05 \\
57.35 \pm 18.16\end{array}$ & & $\begin{array}{l}\mathrm{t}=-0.178 \\
\mathrm{p}=0.859\end{array}$ \\
\hline Family type & $\begin{array}{l}\text { Nuclear } \\
\text { Extended }\end{array}$ & $\begin{array}{l}57.23 \pm 18.47 \\
57.45 \pm 15.66\end{array}$ & & $\begin{array}{l}\mathrm{t}=-0.107 \\
\mathrm{p}=0.915\end{array}$ \\
\hline Current place of residence & $\begin{array}{l}\text { Provincial center } \\
\text { County } \\
\text { Village or Town }\end{array}$ & $\begin{array}{l}58.96 \pm 17.36 \\
55.09 \pm 18.46 \\
56.53 \pm 18.10\end{array}$ & $\begin{array}{l}\mathrm{F}=2.225 \\
\mathrm{p}=0.109\end{array}$ & \\
\hline $\begin{array}{l}\text { Perception of monthly } \\
\text { income level }\end{array}$ & $\begin{array}{l}\text { Expenses less than income } \\
\text { Expenses equal to income } \\
\text { Expenses more than income } \\
\text { Planning pregnancy } \\
\text { Yes } \\
\text { No }\end{array}$ & $\begin{array}{l}56.38 \pm 19.00 \\
58.67 \pm 15.48 \\
58.15 \pm 17.16 \\
\\
57.62 \pm 18.65 \\
56.83 \pm 16.94\end{array}$ & $\begin{array}{l}F=0.701 \\
p=0.496\end{array}$ & $\begin{array}{l}t=0.460 \\
p=0.646\end{array}$ \\
\hline Gestational week & $\begin{array}{l}\leq 12^{\text {th }} \text { week }^{\mathrm{a}} \\
13-27 \text { weeks }^{\mathrm{b}} \\
\geq 28^{\text {th }} \text { week }^{\mathrm{c}}\end{array}$ & $\begin{array}{l}65.82 \pm 14.57 \\
56.54 \pm 17.15 \\
55.08 \pm 18.82\end{array}$ & $\begin{array}{c}\mathrm{F}=9.494 \\
p<0.001 \\
{[a, b][a, c]}\end{array}$ & \\
\hline Gravida & $\begin{array}{l}1 \\
2 \\
3 \\
\geq 4\end{array}$ & $\begin{array}{l}57.41 \pm 19.23 \\
60.22 \pm 16.58 \\
57.23 \pm 17.00 \\
55.31 \pm 17.73\end{array}$ & $\begin{array}{l}F=1.361 \\
p=0.254\end{array}$ & \\
\hline Parity & $\begin{array}{l}\text { Nulliparty } \\
1^{\mathrm{a}} \\
2^{\mathrm{c}} \\
3^{\mathrm{d}} \\
\geq 4^{\mathrm{e}}\end{array}$ & $\begin{array}{l}57.73 \pm 19.10 \\
61.10 \pm 15.17 \\
54.69 \pm 18.15 \\
53.24 \pm 17.64 \\
56.11 \pm 19.31\end{array}$ & $\begin{array}{c}\mathrm{F}=2.658 \\
p=0.019 \\
{[b, d]}\end{array}$ & \\
\hline $\begin{array}{l}\text { Going to the hospital for antenatal visit } \\
\text { regularly since the COVID-19 pandemic }\end{array}$ & $\begin{array}{l}\text { Yes } \\
\text { No }\end{array}$ & $\begin{array}{l}57.69 \pm 17.90 \\
55.61 \pm 17.89\end{array}$ & & $\begin{array}{l}\mathrm{t}=0.985 \\
\mathrm{p}=0.325\end{array}$ \\
\hline $\begin{array}{l}\text { Thinking that COVID-19 may cause } \\
\text { a problem in pregnancy }\end{array}$ & $\begin{array}{l}\text { Yes } \\
\text { No }\end{array}$ & $\begin{array}{l}59.23 \pm 15.18 \\
56.73 \pm 18.56\end{array}$ & & $\begin{array}{l}\mathrm{t}=1.356 \\
\mathrm{p}=0.177\end{array}$ \\
\hline $\begin{array}{l}\text { Thinking that COVID- } 19 \text { may cause } \\
\text { a problem during childbirth }\end{array}$ & $\begin{array}{l}\text { Yes } \\
\text { No }\end{array}$ & $\begin{array}{l}60.32 \pm 14.69 \\
56.33 \pm 18.70\end{array}$ & & $\begin{aligned} \mathrm{t} & =2.274 \\
p & =0.024\end{aligned}$ \\
\hline $\begin{array}{l}\text { COVID- } 19 \text { in one of the family } \\
\text { members/a loved one }\end{array}$ & $\begin{array}{l}\text { Yes } \\
\text { No }\end{array}$ & $\begin{array}{l}64.77 \pm 14.99 \\
55.21 \pm 18.10\end{array}$ & & $\begin{array}{r}\mathrm{t}=5.278 \\
p<0.001\end{array}$ \\
\hline $\begin{array}{l}\text { Following COVID-19-related } \\
\text { developments }\end{array}$ & $\begin{array}{l}\text { Yes } \\
\text { No }\end{array}$ & $\begin{array}{l}57.84 \pm 17.94 \\
51.38 \pm 16.59\end{array}$ & & $\begin{array}{r}\mathrm{t}=2.159 \\
p=0.031\end{array}$ \\
\hline $\begin{array}{l}\text { Monitoring the number of COV-19 } \\
\text { cases/ deaths/recovering patients in } \\
\text { Turkey }\end{array}$ & $\begin{array}{l}\text { Yes } \\
\text { No }\end{array}$ & $\begin{array}{l}58.73 \pm 18.23 \\
55.09 \pm 17.22\end{array}$ & & $\begin{array}{l}\mathrm{t}=2.107 \\
p=0.036\end{array}$ \\
\hline
\end{tabular}

Turkey

Abbreviations: mean; SD: standard deviation; PCL-5; DSM-5: post-traumatic stress disorder checklist;

F: One-way ANOVA test; t: Independent sample t-test; p: statistical significance

Note: The letters a, b, c, d, and e indicate the group that makes the difference. Italics values are statistically significant 
Table 5. The correlation between the number of daily COVID-19 cases/deaths/recovering patients in Turkey and the total mean scores of PCL-5 of pregnant women $(n=267)$

\begin{tabular}{lcc}
\hline Monitoring the number of COVID-19 cases/deaths/recovering patients in Turkey & $\mathrm{r}$ & $\mathrm{p}$ \\
\hline Monitoring the number of COVID-19 cases & 0.268 & $<0.001$ \\
Monitoring the number of COVID-19 deaths & 0.319 & $<0.001$ \\
Monitoring the number of COVID-19 recovering patients & 0.222 & $<0.001$ \\
\hline
\end{tabular}

Abbreviations: r: Pearson's correlations coefficients; p: statistical significance; PCL-5, DSM-5 post-traumatic stress disorder checklist; Note: Italics values are statistically significant

\section{DISCUSSION}

It is known in the literature that pregnant women experience mental problems (Dikmen Yildiz et al. 2017, Liu et al. 2021, Zhou et al. 2020). They can adversely affect physical, cognitive, and emotional development in fetal (Wu et al. 2020b) and childhood periods (ClosaMonasterolo et al. 2017) while mental problems experienced during pregnancy cause obstetric adverse outcomes (Cook et al. 2018). Compulsory measures taken due to the COVID-19 pandemic, uncertainty about the future, and changes in current living standards have created stress (Esterwood \& Saeed 2020). Therefore, it is important to determine the effect of such a global crisis on the mental health of pregnant women.

The mean total PCL-5 scale score of the pregnant women was found to be $57.27 \pm 17.90$ (Table 3 ). The total mean scores of pregnant women in the COVID-19 pandemic were found to be $36.60 \pm 15.65$ and $36.9 \pm 10.1$, respectively in another study by Hocaoglu et al. (Turkey) and Saccone et al. (Italy) evaluating PTSD symptoms (2020) (Hocaoglu et al. 2020, Saccone et al. 2020). A study conducted in China (Zhou et al. 2020) found that approximately one in 10 pregnant women exhibited symptoms of PTSD at the clinical level. Liu et al. (USA) also found that women in the perinatal (antenatal and postpartum) period had clinical level PTSD symptoms (Liu et al. 2021). PTSD symptoms of pregnant women during the pandemic were found to be higher in the study of Berthelot et al. (Canada) (Berthelot et al. 2020). Current studies in various countries show that pregnant women experience PTSD symptoms in the COVID-19 pandemic even though the assessment tools vary. Our research results reveal that the pandemic causes PTSD symptoms in pregnant women.

The mean scores of pregnant women in the re-experiencing, avoidance, negative alterations, and hyperarousal sub-scales of the PCL-5 scale were found to be $13.81 \pm 4.71,5.64 \pm 1.92,20.00 \pm 6.43$, and $17.81 \pm 5.75$, respectively, in our study. The mean scores of pregnant women were found to be $16.68 \pm 8.18$ for re-experiencing, $12.99 \pm 6.05$ for avoidance, and $9.84 \pm 6.32$ for hyperarousal in a study of pregnant women with a history of perinatal loss (2018) (Sabanc1 2018). Re-experiencing symptoms were found to be $15.00 \pm 4.12$, avoidance symptoms $18.35 \pm 5.11$, and arousal symptoms $14.13 \pm 4.50$ in another study evaluating PTSD symptoms according to DSM-IV criteria of women with perinatal complications (preeclampsia, eclampsia, postpartum bleeding)
(Em 2011). Current results suggest that past events occurred again in pregnant women and women after these life-threatening and traumatic conditions, causing avoidance behaviors and arousal symptoms. Our study reveals that the pandemic causes more negative alterations and hyperarousal symptoms in pregnant women.

The difference between the age of pregnant women and PTSD symptoms was found to be statistically insignificant in our study $(p>0.05)$. Hocaoglu et al. found that maternal age was not effective in PTSD symptoms in parallel with our study $(p>0.05)$ (Hocaoglu et al. 2020). Liu et al.'s study with women in the perinatal process also supports our research results (Liu et al. 2021). The fact that the pregnant women who participated in our study cover a wide range of reproductive ages between the ages of 19-47 and the scores obtained are above the average shows that it is important to evaluate pregnant women of all ages during the pandemic in terms of PTSD symptoms.

No statistically significant difference was found between the education level of pregnant women and PTSD symptoms in our study $(p>0.05)$. However, the mean PCL-5 scores of pregnant women with high school education and above were higher. PTSD symptoms were found to increase as the level of education increased in the study of Hocaoglu et al. (Hocaoglu et al. 2020). It was suggested that the high education level increased PTSD symptoms due to the pandemic even though it was determined in our study that the education levels of pregnant women did not affect PTSD symptoms.

It was determined that employment status, family type, and current place of residence did not affect PTSD symptoms of pregnant women in our study $(p>0.05)$. It has been found, in the study of Hocaoglu et al., that employment status (Hocaoglu et al. 2020) and, in the study of Liu et al., living with a spouse/partner does not affect PTSD symptoms (Liu et al. 2021). No data were found in the literature on the current place of residence. The results of our study reveal that every pregnant woman experiences PTSD symptoms due to COVID-19 pandemic, regardless of their working status, cohabitants, and place of residence.

No statistically significant difference was found between pregnancy planning and PTSD symptom level in our study $(p>0.05)$. However, it was determined that the PTSD symptom level of the pregnant women in the first trimester $\left(\leq 12^{\text {th }}\right.$ week $)$ was the highest, and the difference between the pregnant women in the second (13-27 weeks) and third trimester ( $\geq 28^{\text {th }}$ week) was statistically 
significant $(p<0.05)$. It was found in the study of Saccone et al. that the mean scores of pregnant women in their first trimester were the highest and the difference was statistically significant $(p<0.05)$ (Saccone et al. 2020). Hocaoglu et al. found that gestational week did not affect PTSD symptoms contrary to our study results (Hocaoglu et al. 2020). The higher mean PTSD score of the pregnant women in the $1^{\text {st }}$ trimester may be due to the fact that the pregnant women at the beginning of pregnancy think that COVID-19 may adversely affect the growth and development of the baby.

Both gravidity and parity were found not to affect PTSD symptom level in the study of Hocaoglu et al. $(p>0.05)$ (Hocaoglu et al. 2020). No statistically significant difference was found between gravidity and PTSD symptom levels in our study $(p>0.05)$. There was statistically significant differences between the women's parity and PTSD symptom levels $(p<0.05)$. It was found in our study that the mean scores of pregnant women with $2^{\text {nd }}$ pregnancy and pregnant women with 1 living child were the highest at the same time (Table 2). It was determined that the mean scores of pregnant women who regularly went to the hospital for antenatal visit during the COVID-19 pandemic were higher in addition to this (Table 2). Liu et al. $(p<0.001)$ found that COVID-19-related health anxiety was associated with PTSD symptoms at the clinical level in their study with women in the perinatal period (Liu et al. 2021). It is thought that their symptom levels increase because they care more about the risk of transmission in those who have a second pregnancy and have 1 child when these results of the pregnant women participating in our study and their practices during the pandemic process (wearing masks and washing their hands, paying attention to personal distance, not going out unless there is an emergency, etc.) are evaluated.

It was determined in our study that the PTSD symptom levels of pregnant women who thought that the COVID-19 would cause a problem in pregnancy were higher. In addition, PTSD symptom levels were found to be significantly higher in pregnant women who thought that the pandemic would cause problems in childbirth $(p<0.05)$. Yassa et al. found that $31.4 \%$ $(67 / 213)$ of pregnant women thought that they and $48.9 \%(104 / 213)$ of their babies would be infected with COVID-19 in their study in Turkey covering the first day of COVID-19 detection and the next 10 days (Yassa et al. 2020). Approximately $1 / 4$ of the pregnant women participating in our study thought that COVID19 would be transmitted during pregnancy and childbirth. This shows that some of the pregnant women thought that COVID-19 would be transmitted during childbirth since the first days of the pandemic. PTSD usually occurs 1 month after the traumatic events (Psychiatric Association of Turkey 2021). It reveals that the idea that pregnant women will have problems during this process during pregnancy and childbirth develops PTSD symptoms due to the pandemic at a remarkable level.
Liu et al. found that COVID-19-related health anxieties and grief caused by loss experiences due to the COVID-19 pandemic increased PTSD symptoms of women in the perinatal period $(p<0.001)$ (Liu et al. 2021). PTSD symptom levels were found to be significantly higher in pregnant women with one of the family members/a loved one with COVID-19 in our study $(p<0.001)$. Our research results suggest that the thought of losing loved ones due to the pandemic increases PTSD symptom levels.

$\mathrm{Wu}$ et al. found that the number of cases $\geq 500$ increased the risk of depression of pregnant women $(\mathrm{Wu}$ et al. 2020c). PTSD symptom levels were found to be higher in pregnant women following COVID-19-related developments compared to those who did not in our study $(p=0.031)$. The mean scores of the pregnant women who followed the number of COVID-19 cases/ deaths/recovering patients in Turkey were found to be significantly higher $(p=0.036)$ (Table 4$)$. However, it was determined that there was a positive significant relationship between the number of cases/deaths/recovering patients and PTSD symptom levels $(\mathrm{r}=0.268$, $\mathrm{r}=0.319, \mathrm{r}=0.222$, respectively; $p<0.001$ ) (Table 5). PTSD is defined as re-experiencing trauma after frightening life events, having reminder thoughts, avoiding emotions and interactions, and seeing negative changes in cognition and mood (Eren Koçak \& Kılıç 2017). It is thought that the level of PTSD symptoms of pregnant women is increased by following the developments related to COVID-19, causing them to experience the pandemic continuously and to be exposed to thoughts reminding of it in line with the results obtained from our study.

\section{Limitation of the study}

This study has some limitations. Firstly, our study was conducted in a single center in Turkey and the results can therefore be generalized only to pregnant women living in that province and in a similar age group. Secondly, limitation is due to the self-reporting of the levels of psychological impact, post-traumatic stress disorder symptoms which may not always be aligned with objective assessment by health professionals.

\section{CONCLUSION}

It was determined in the present study that the COVID-19 pandemic caused post-traumatic stress disorder symptoms in pregnant women. It was determined that pregnant women of almost all ages experienced PTSD symptoms regardless of education level, employment status, individuals they lived with, place of residence, and perception of monthly income level. However, our study results show that PTSD symptom levels are highest in pregnant women in the first trimester, who gave birth once and went to antenatal follow-up regularly. The thinking of having problems during childbirth due to the pandemic, the 
infection of one of the family members/a loved one with COVID-19, the follow-up of the situation in Turkey related to COVID-19 significantly affect the PTSD symptoms of pregnant women.

\section{Implications for health professional practice}

Our research results reveal that the traumatic effects of the COVID-19 pandemic cause PTSD symptoms in pregnant women. Health professionals should take an active role, especially in the antenatal process in order to protect and improve maternal, fetal, and newborn health during the pandemic. It is important in outpatient follow-up to question the effects of the pandemic on the mental health of pregnant women, to determine them, and to refer pregnant women to psychiatric/psychological counseling centers when deemed necessary. Health professionals' determination of psychological needs of pregnant women in accordance with each trimester and teaching effective coping strategies in line with the pandemic may increase the positive pregnancy and childbirth experiences of pregnant women. The use of different technological means of communication, where appropriate, may support the provision of effective care taking into account the psychopathology experienced by pregnant women due to their coming to antenatal follow-ups. Health professionals providing psychosocial support to pregnant women and providing professional counseling services may increase the quality of care by increasing the prevalence of telehealth services.

\section{Acknowledgements:}

We would like to thank all the women who were willing to participate in this study.

\section{Conflict of interest: None to declare.}

\section{Contribution of individual authors:}

Pınar Kara \& Evşen Nazik: the conception and design of the study, analysis and interpretation of data, drafting the article or revising it critically for important intellectual content.

Hakan Nazik \& Dilara Özer: the conception and design of the study, acquisition of data, drafting the article or revising it critically for important intellectual content.

All authors approved the final manuscript.

\section{References}

1. Berthelot N, Lemieux R, Garon-Bissonnette J, DrouinMaziade C, Martel É \& Maziade M: Uptrend in distress and psychiatric symptomatology in pregnant women during the coronavirus disease 2019 pandemic. Acta Obstet Gynecol Scand 2020; 99:848-855. https://doi.org/10.1111/aogs.13925

2. Bjelica A, Cetkovic N, Trninic-Pjevic A \& MladenovicSegedi L: The phenomenon of pregnancy-a psychological view. Ginekol Pol 2018; 89:102-106. https://doi.org/10.5603/GP.a2018.0017

3. Boysan M, Özdemir PG, Özdemir O, Selvi Y, Yllmaz E \& Kaya N: Psychometric properties of the Turkish version of the PTSD checklist for diagnostic and statistical manual of mental disorders, fifth edition (PCL-5). Psychiatry and Clinical Psychopharmacology 2017; 27:306-316. https://doi.org/10.1080/24750573.2017.1342769

4. Cirino NH \& Knapp JM: Perinatal posttraumatic stress disorder: A review of risk factors, diagnosis, and treatment. Obstetrical and Gynecological Survey 2019; 74:369-376. https://doi.org/10.1097/OGX.0000000000000680

5. Closa-Monasterolo R, Gispert-Llaurado M, Canals J, Luque V, Zaragoza-Jordana $M$, Koletzko $B$ et al.: The effect of postpartum depression and current mental health problems of the mother on child behaviour at eight years. Matern Child Health J 2017; 21:1563-1572. https://doi.org/10.1007/s10995-017-2288-x

6. Cook N, Ayers $S \&$ Horsch A: Maternal posttraumatic stress disorder during the perinatal period and child outcomes: a systematic review. J Affect Disord 2018; 225:18-31. https://doi.org/10.1016/j.jad.2017.07.045

7. Demirezen GN: The symptoms of PTSD in women who are residents of shelters and were exposed to IPV: An investigation in the frame of cognitive model by ehlers \& clark. Istanbul Şehir University Institute of Social Sciences, Department of Clinical Psychology, Master's Program, 2019, Istanbul, Turkey

8. Dikmen Yildiz P, Ayers $S \&$ Phillips L: The prevalence of posttraumatic stress disorder in pregnancy and after birth: $A$ systematic review and meta-analysis. J Affect Disord 2017; 208:634-645. https://doi.org/10.1016/j.jad.2016.10.009

9. Em P: To examine the symptoms of re-conception, anxietydepression and post-traumatic stress disorder in women whose pregnancy was complicated by severe preeclampsia or peripartum hemorrhage. Dicle University Faculty of Medicine, Department of Obstetrics and Gynecology, Medical Thesis, 2011, Diyarbakur, Turkey

10. Eren Koçak E \& Kllıç C: Cognitive impairments in posttraumatic stress disorder. Turk Psikiyatri Derg 2017; 28:124-131. https://doi.org/10.5080/u18276.

11. Esterwood E \& Saeed A: Past epidemics, natural disasters, COVID19, and mental health: learning from history as we deal with the present and prepare for the future. Psychiatr Q 2020; 91:121-1133. https://doi.org/10.1007/s11126-020-09808-4

12. Hocaoglu M, Ayaz R, Gunay T, Akin E, Turgut A \& Karateke A: Anxiety and post-traumatic stress disorder symptoms in pregnant women during the COVID-19 pandemic's delay phase. Psychiatr Danub 2020; 32:521526. https://doi.org/10.24869/psyd.2020.521

13. Li SH \& Graham BM: Why are women so vulnerable to anxiety, trauma-related and stress-related disorders? The potential role of sex hormones. Lancet Psychiatry 2017; 4:73-82. https://doi.org/10.1016/S2215-0366(16)30358-3

14. Liu CH, Erdei $C$ \& Mittal L: Risk factors for depression, anxiety, and PTSD symptoms in perinatal women during the COVID-19 pandemic. Psychiatry Res 2021; 295:1-7. https://doi.org/10.1016/j.psychres.2020.113552

15. Ministry of Health: COVID-19 Information. Retrieved from https://covid19.saglik.gov.tr/

16. Psychiatric Association of Turkey: Posttraumatic stress disorders. Retrieved from https://www.psikiyatri.org.tr/halkayonelik/28/travma-sonrasi-stres-bozuklugu 
17. Sabancı E: Post-traumatic stress disorder and affecting factors in couples after perinatal loss. İn̈nü University Institute of Health Sciences, Department of Midwifery, Master Thesis, 2018, Malatya, Turkey

18. Saccone G, Florio A \& Venturella R: Psychological impact of coronavirus disease 2019 in pregnant women. Am J Obstet Gynecol 2020; 223:293-295. https://doi.org/0.1016/j.ajog.2020.05.003

19. Weathers FW, Litz BT, Keane TM, Palmieri PA, Marx BP \& Schnurr PP: The PTSD checklist for DSM-5 (PCL-5). Retrieved from https://www.ptsd.va.gov/professional/ assessment/adult-sr/ptsdchecklist.asp

20. World Health Organization: WHO announces COVID-19 outbreak a pandemic. (2021a). Retrieved from https://www.euro.who.int/en/health-topics/healthemergencies/coronavirus-covid-19/news/news/2020/3/ who-announces-covid-19-outbreak-a-pandemic

21. World Health Organization: Coronavirus Disease 2019. $2021 \mathrm{~b}$. Retrieved from http://www.euro.who.int/en/healthtopics/health-emergencies/coronavirus-covid-19/novelcoronavirus-2019-ncov

22. World Health Organization: Long-term effects of COVID19. 2021c. Retrieved from https://www.who.int/docs/defaultsource/coronaviruse/risk-comms-updates/update-36-longterm-symptoms.pdf?sfursn $=5 d 3789 a 6 \_2$
23. Wu Y-C, Chen C-S \& Chan Y-J: The outbreak of COVID19: an overview. Journal of the Chinese Medical Assocciation 2020a; 83:217-220. https://doi.org/10.1097/JCMA.0000000000000270

24. Wu Y, Lu Y-C, Jacobs M, Pradhan S, Kapse K, Zhao L et al.: Association of prenatal maternal psychological distress with fetal brain growth, metabolism, and cortical maturation. JAMA Netw Open 2020b; 3:e1919940. https://doi.org/10.1001/jamanetworkopen.2019.19940

25. Wu Y, Zhang C, Liu H, Duan C, Li C, Fan J et al.: Perinatal depressive and anxiety symptoms of pregnant women during the coronavirus disease 2019 outbreak in China. Am J Obstet Gynecol 2020c; 223:240.e1-9. https://doi.org/10.1016/j.ajog.2020.05.009

26. Yassa M, Birol P, Yirmibes C, Usta C, Haydar A, Yassa $A$ et al.: Near-term pregnant women's attitude toward, concern about and knowledge of the COVID-19 pandemic. J Matern Fetal Neonatal Med 2020; 33:38273834. https://doi.org/10.1080/14767058.2020.1763947

27. Zhou Y, Liu Z, Peng S, Peng S, Wang R, Qi L et al.: The prevalence of psychiatric symptoms of pregnant and non-pregnant women during the COVID-19 epidemic. Translational Psychiatry 2020; 10:1-7. https://doi.org/10.1038/s41398-020-01006-x

\section{Correspondence:}

Research Assistant Pınar Kara, RN

Hemşirelik Bölümü, Doğum ve Kadın Hastalıklarn Hemşireliği ABD.,

Niğde Ömer Halisdemir Üniversitesi Niğde Zübeyde Hanım Să̆lık Yüksekokulu

Derbent Yerleşkesi, 51200, Merkez, Niğde, Turkey

E-mail:karapinar@hotmail.com 